\title{
Management of tongue-tie in children: a case report
}

\author{
FZ. Benkarroum ${ }^{1}$, Fawzi R ${ }^{2}$ \\ ${ }^{1}$ FZ. Benkarroum Resident in Pediatric and Preventive Dentistry service, ${ }^{2}$ Fawzi R Professor and Chief of Department \\ of Pediatric and Preventive Dentistry CCTD - Faculty of Dentistry of Rabat, Morocco
}

Address for Correspondence: BENKARROUM Fatima Zahra, Consultation Center of Dental Treatment Rabat Faculty of Dentistry, Avenue Allal El Fassi, Mohammed Jazuli Street - Al Irfane City - BP, Rabat Institutes f.z.benkarroum@gmail.com

\begin{abstract}
Introduction: tongue-tie or ankyloglossia, is a congenital condition that results when the inferior lingual frenulum is too short and is attached to the tip of the tongue, limiting its normal movements. The restriction of lingual mobility during childhood and adolescence can cause alterations in bone growth of the orofacial structures and the oral functions of the child. Also it affects speech; feeding, oral hygiene as well as social environment. Ankyloglossia can be observed at different ages with specific indications for treatment for each group. Case Report: The aim of this article is to relate a case of ankyloglossia in a boy child of seven-year-old who was examined in the department of pediatrics in the center of Consultations and Dental Treatment of Rabat. According to Kotlow's classification the child was diagnosed with type III ankyloglossia and treated by frenectomy followed by speech therapy for an immediate rehabilitation. A marked improvement in the movement of the tongue was observed at follow up visits in the treated case. Discussion and Conclusion: The routine examination of the lingual frenulum permits the identification of insertion abnormalities and enables the establishment of the most appropriate therapeutic approaches.
\end{abstract}

Key words: Ankyloglossia, Tongue-tie, Frenectomy

\section{Introduction}

Tongue tie or ankyloglossia is a congenital variation characterized by a short lingual frenulum which may result in restriction of tongue mobility and thus impact on function. [1]. Etymologically, the term "ankyloglossia" originates from the Greek words "agkilos" (curved) and "glossa" (tongue). The first use of the term "ankyloglossia" in the medical literature dates back to the 1960s, when Wallace defined tonguetie as "a condition in which the tip of the tongue cannot be protruded beyond the lower incisor teeth because of a short frenulum linguae, often containing scar tissue" [2] [3]. The incidence of tongue tie varies from $0.2 \%$ $5 \%$, with a male child predilection. There is continuing controversy over the diagnostic criteria and treatment of ankyloglossia[4]. Several studies establish diagnostic

Manuscript received: $2^{\text {nd }}$ March 2016 Reviewed: $12^{\text {th }}$ March 2016

Author Corrected; $25^{\text {th }}$ March 2016

Accepted for Publication: $8^{\text {th }}$ April 2016 criteria based on the length of the lingual frenulum, amplitude of tongue movement $[5,6,7,8]$, heart-shaped look when the tongue is protruded and/or thickness of the fibrous membrane $[9,10,11]$.

In children, ankyloglossia can lead to breastfeeding difficulties, uncoordinated sucking, speech disorders, poor oral hygiene, malocclusion, gingival recession and bullying during childhood and adolescence. $[12,13]$.

The purpose of the present article was to describe a clinical case of ankyloglossia, which was treated by lingual frenectomy followed by speech therapy for an immediate rehabilitation of the lingual muscle. Additionally, information on the indications, surgical techniques for the treatment of ankyloglossia in children were presented. 


\section{Case Report}

A seven-year-old boy child accompanied by his mother, presented at the service of Pediatric dentistry of the Center of Consultations and Dental Treatment of Rabat for management of the oral condition. The general examination didn't reveal any particular general pathology nor known drug allergy.

The extraoral examination revealed a straight facial profile, lower lip protrusion, and a dolichofacial pattern. The intraoral clinical examination showed promandibulie [Fig 1] with anterior open bite, interincisal diastema and worsening of the growth pattern as the tongue assumes a lower position.

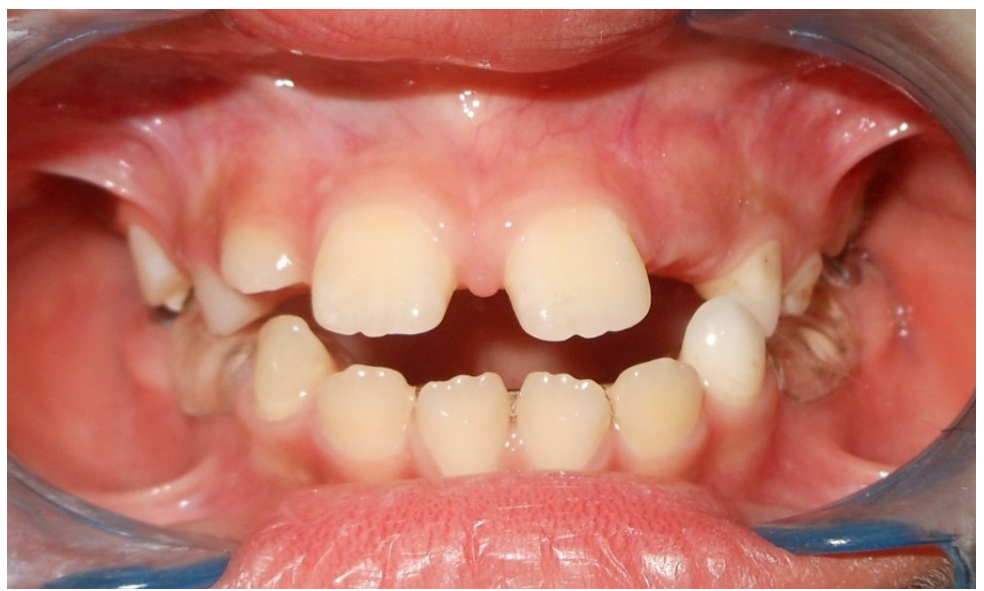

Fig 1: Intraoral view showing the promandibulie with anterior open bite and interincisal diastema.

The frenulum was a short, thick, fibrosed and smaller in length [Fig 2]. When subject was asked to protrude, reduced tongue movements were observed with inability to protrude the tongue fully, impossibility of the tongue to touch with its tip the retro-incisal papilla on the palate. A heart shape during lingual protrusion, reduction of sublingual space, space between central inferior incisors due to the tensile force exerted by the lingual frenum during speech and deglutition were also noted [Fig 3], the child showed also speech difficulties.

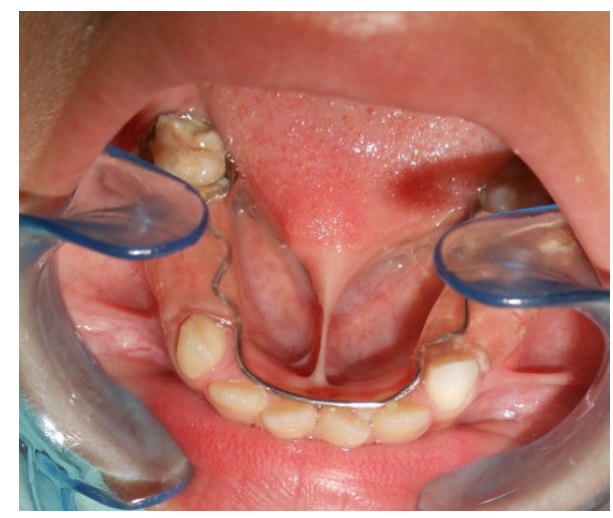

Fig 2: Endobuccal view showing Ankyloglossia, short and tight lingual frenulum.

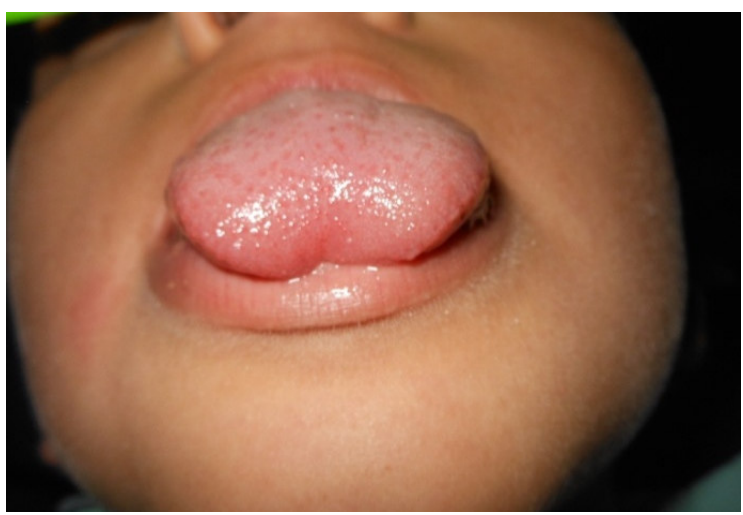

Fig 3: Clinical aspect of the tongue during protrusion; heart-shaped tongue.

The diagnosis of reduced tongue mobility was retained and lingual frenectomy was indicated and was conducted with parental consent. Before surgical treatment, the assessment of oral status was systematic to reduce oral sepsis and perform surgery under better conditions. 
Treatment was realized under topical anesthesia (2\% lidocaine with 1:100,000 epinephrine) on tongue's inferior surface [Fig 4]. After achieving good anesthesia, two hemostats (one curved and the other straight) were placed against the tissues over the superior and inferior aspects of the frenulum, respectively, with their tips meeting in the deep aspect near the base of the tongue. The incision was made with a $\# 15 \mathrm{c}$ blade following the hemostatic pliers, cutting through the upper aspect of the frenulum [Fig 5]. Fiber remnants were excised, blunt dissection was performed and 4-0 non resorbable silk sutures were placed over the wound.

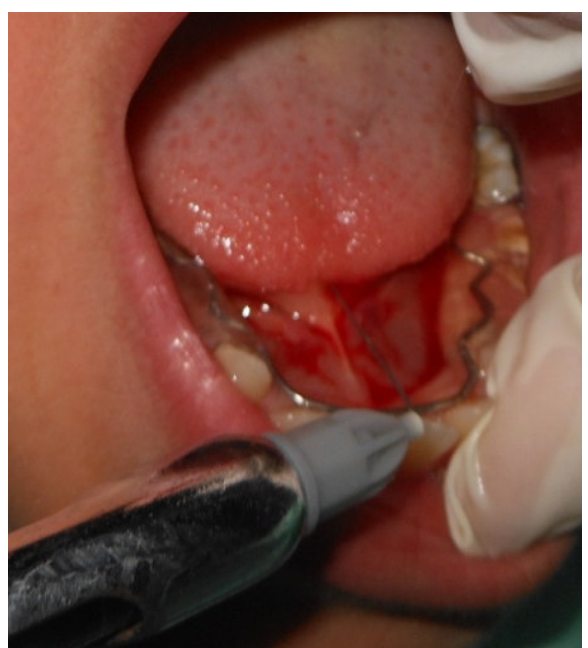

Fig 4: Infiltrative anesthesia of the lingual nerve

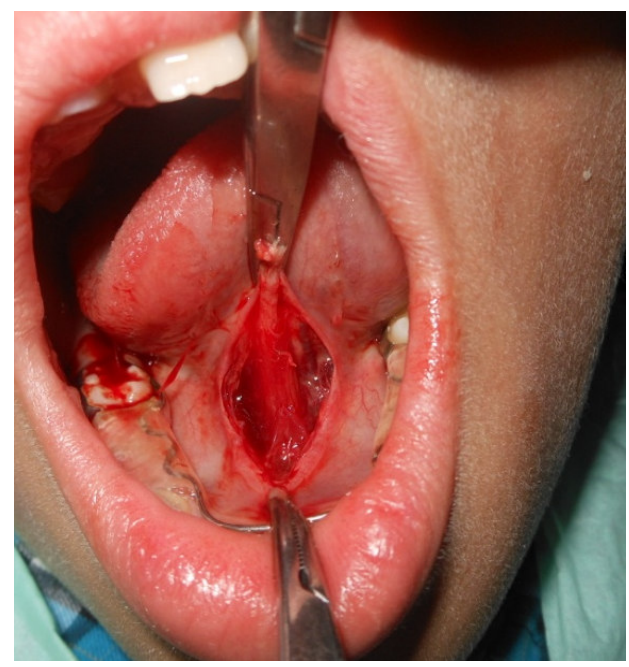

Fig 5: Excised triangular tissue held with the hemostats and excision of fiber remnants.

Tension free closure was checked through the insertion of the first suture at the middle of the wound. Additional sutures were placed along the tongue base and on the floor of the mouth. [Fig 6]

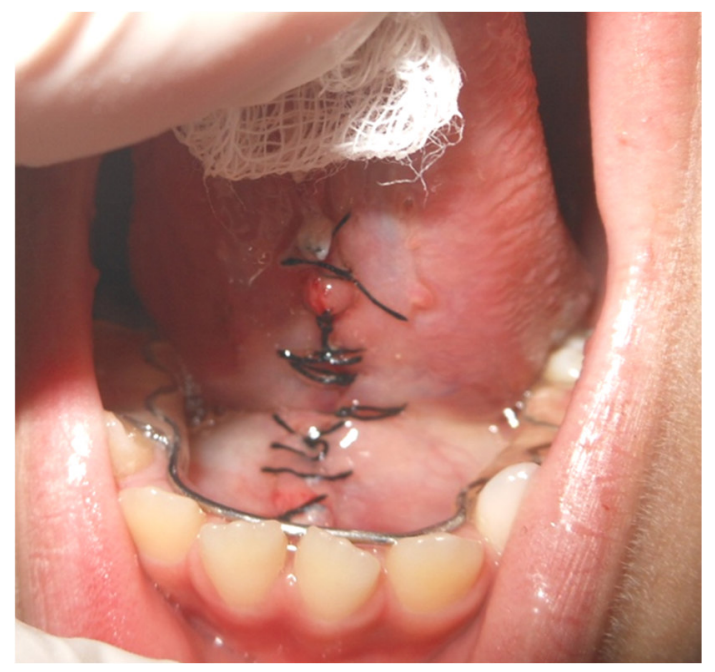

Fig 6 : Silk sutures placed over the wound

Postoperative care includes paracetamol, mouthwash containing chlorhexidine, as well as recommendations on diet and maintaining good oral hygiene. The postoperative period was uneventful. After one week, the remaining sutures were removed [Fig 7]. The tongue was evaluated and early mobilization was indicated to minimize scarring and improve tongue range of motion. Patient is asked to perform tongue exercises that are designed to improve protrusion, elevation, and side-to-side motion 3 or more times daily. 


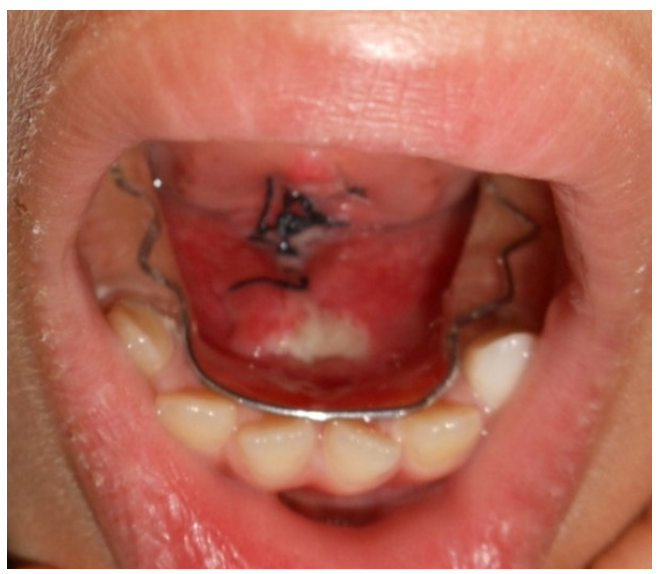

Fig 7 : Clinical aspect of the surgical site on the seventh postoperative day

Patient was referred to a speech therapist to have his tongue movement and speech articulation improved.

Although some improvement in tongue mobility occurred in the early postoperative period, a noticeable gain in mobility has been noted 1month postoperatively [Fig 8,9]. Further improvements were observed 3 months after surgery.
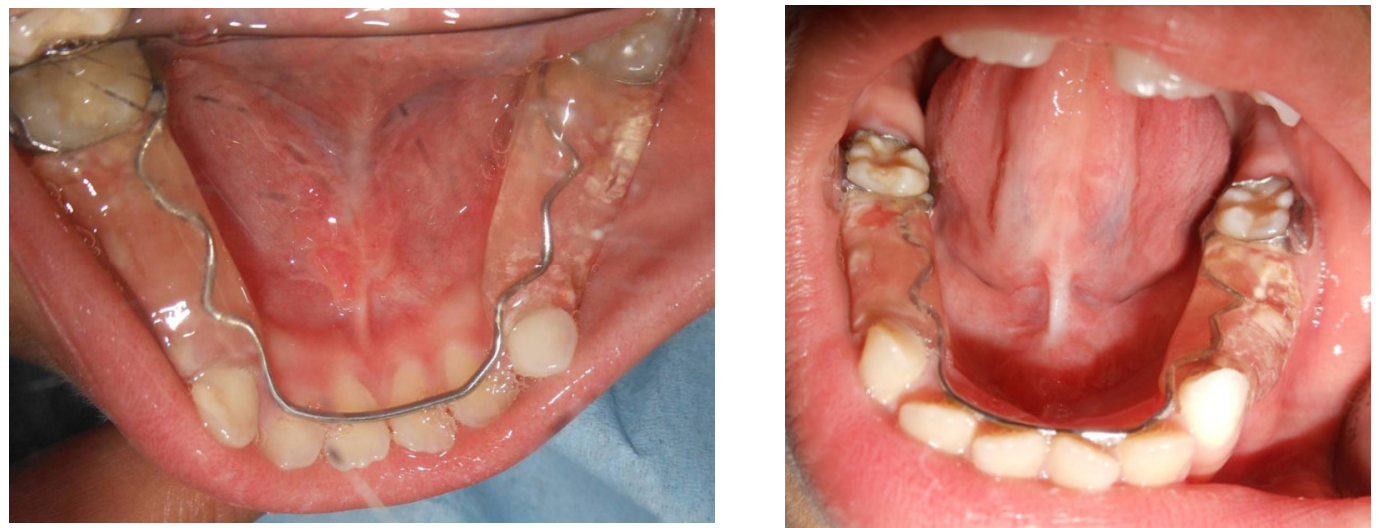

Fig 8, 9: control visit one month after surgery showing easier lingual mobility

The child was followed-up for 6 months postoperatively, with no recurrence and nor difficulty in phonetics and during intake of food, such fact suggested an excellent prognosis for the case.

[Fig 10, Fig 11, Fig 12]

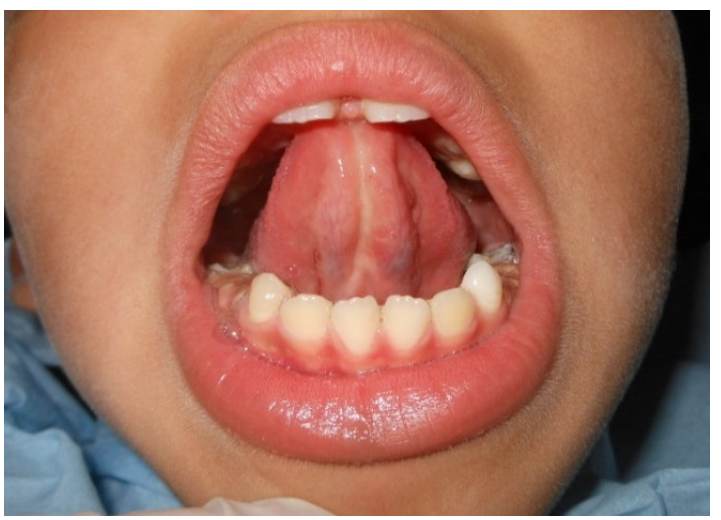

Fig 10: The child mouth wide open can touch with the tip of his tongue the retro-incisal papilla on the palate 

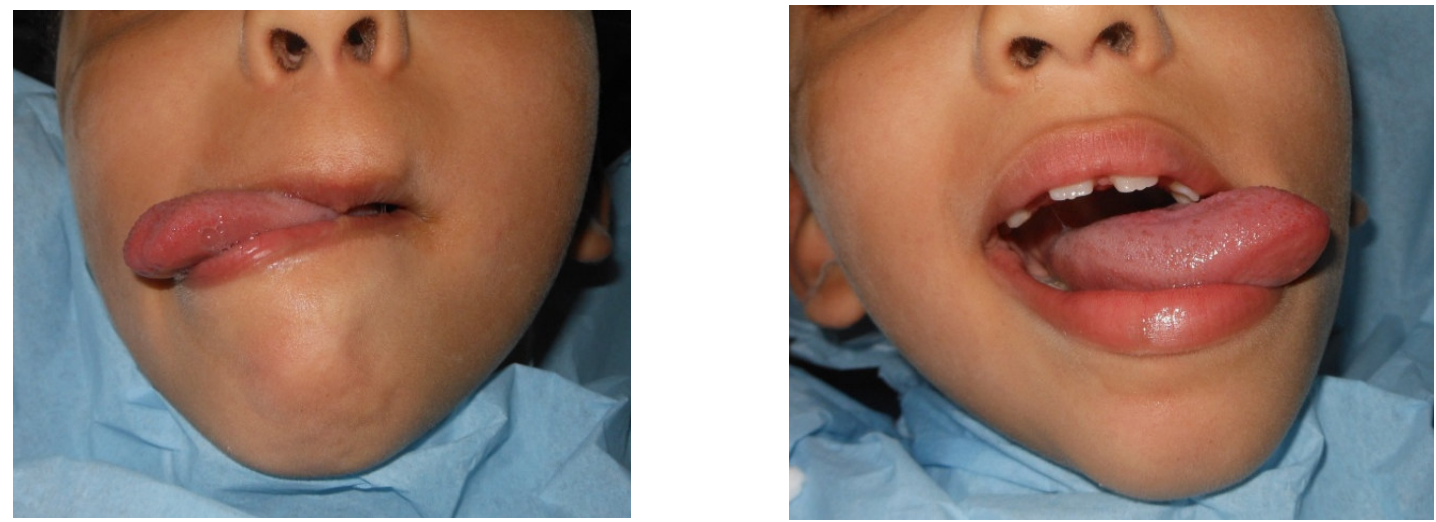

Fig 11: Lateral tongue movements ( left and right)

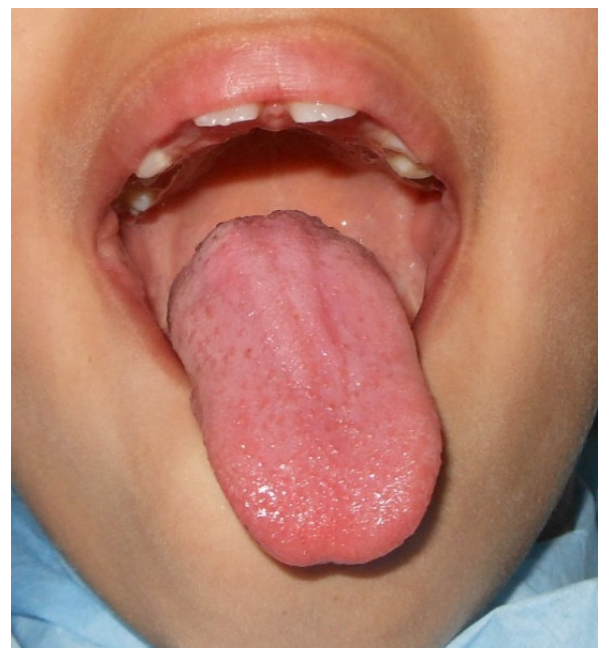

Fig 12 : Easy lingual propulsion

At this stage the patient was sent to Dentofacial orthopedics service for the treatment of 3rd class malocclusion due to the low lingual position which cause an excessive development of mandibular bone and an hypo development of maxillary bone that wasn't driven in its expansion by the tongue thrust.

\section{Discussion}

Opinions range widely regarding the significance of ankyloglossia. This term has been used to describe different situations, such as a tongue that is fused to the floor of the mouth as well as a tongue with impaired mobility due to a short and thick lingual frenulum. [14]

According to Kotlow's classification, tongue tie is classified as Class I (Mild Ankyloglossia: 12-16mm), Class II (Moderate Ankyloglossia: 8-11mm), Class III (Severe Ankyloglossia: 3-7 $\mathrm{mm}$ ) and Class IV(Complete Ankyloglossia: Less than 3mm) [15]. According to this classification our case was of Class
III severe ankyloglossia with tongue protrusion of 5 $\mathrm{mm}$.

Hazelbaker [16] developed a descriptive assessment tool for lingual frenulum function; however, it is complex, lengthy and has not been validated in a controlled manner. [17]

Ankyloglossia or Tongue tie affects speech, feeding, oral hygiene as well as social environment. It causes blanching of soft tissue during tongue retrusion and also exerts force on mandibular anteriors. [18] 
Moreover, it interferes in tooth brushing process, consequently, favoring the risk of plaque accumulation, tissue inflammation onset, and gingival recession. [19]

In our case, ankyloglossia is associated with Class III malocclusion. However there is limited evidence to show that ankyloglossia and abnormal tongue position may affect skeletal development and be associated with malocclusion. [20, 21]. A complete orthodontic evaluation, diagnosis, and treatment plan are necessary prior to any surgical intervention. [21, 13]. Histologically, the lingual frenulum is composed of a conjunctive tissue rich in collagen and elastic fibers, with some muscular fibers, blood vessels, and fat cells, covered by a stratified pavimentous epithelium. [22]

Children diagnosed with ankyloglossia were subjected to different therapeutic approaches. The choice of the therapeutic depends on the impacts associated with tongue-tie: $[23,24,25,26]$

- If they are non-existent or very low, the practitioner will refrain from making a surgical intervention and speech therapy will be proposed.
- If the functional effects are orthophonics or orthodontics, surgery will be performed as soon as possible.

- If we have localized gingival recession on the lingual aspect of the mandibular incisors associated with ankyloglossia, elimination of plaque-induced gingival inflammation can minimize gingival recession without any surgical intervention. [27]. When recession continues even after oral hygiene management, surgical intervention may be indicated. [27] [13]

- If other impacts are noted, the need for a surgical treatment will be studied case by case.

- If ankyloglossia is very severe, surgery will be immediately proposed.

Nowadays, several surgical techniques have been described to correct an abnormal frenulum: frenotomy and frenectomy[28]. In the case presented in this article, we opted for frenectomy technique. This choice was based on appropriate circumstances carefully evaluated preoperatively.

We illustrate the therapeutic approach proposed above by the following scheme [Fig 13].

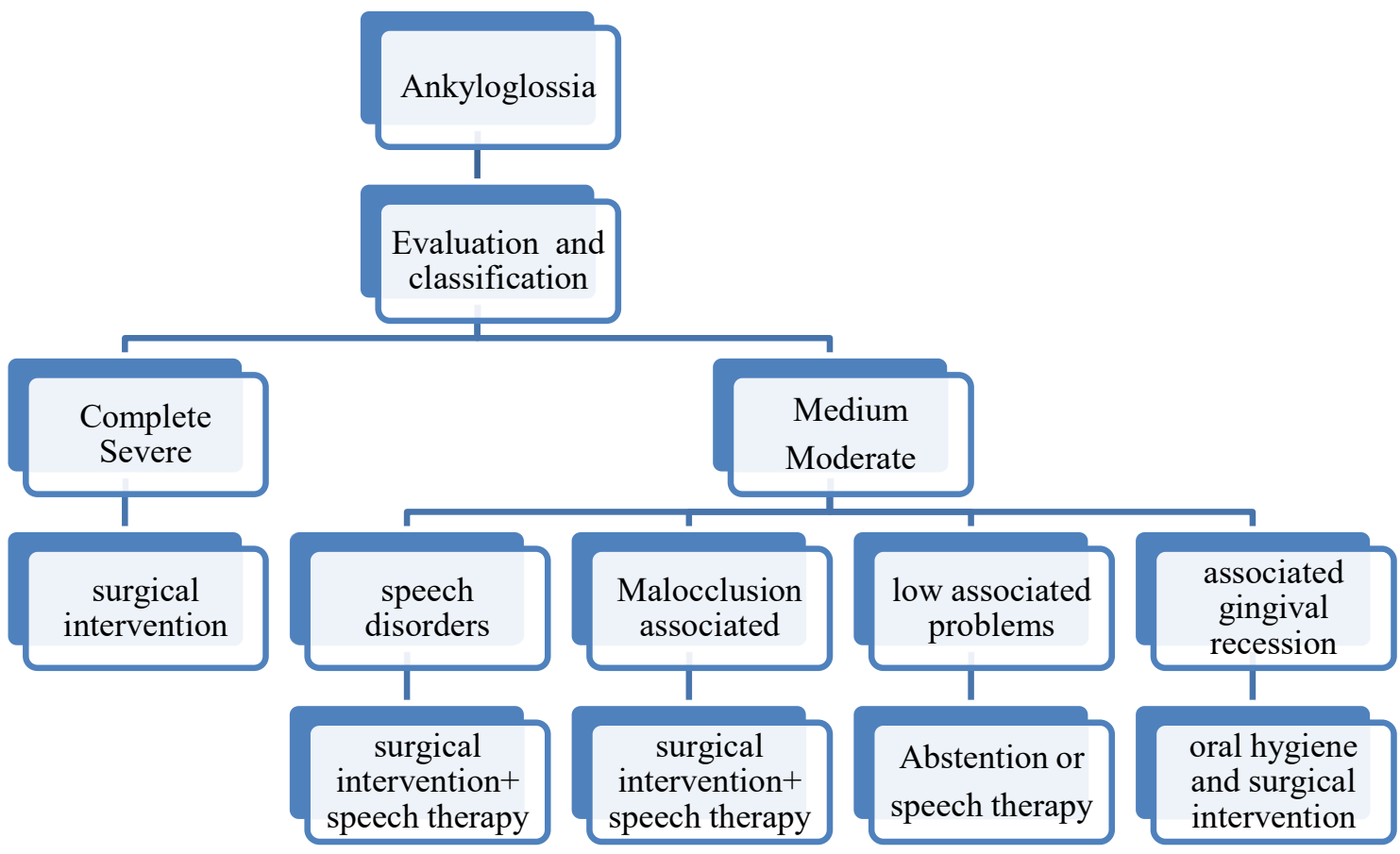

Fig 13: Decision tree facing ankyloglossia 
Based on available evidence, frenotomy (the clipping of the lingual frenulum) cannot be recommended for all infants with ankyloglossia. It is the most indicated technique for babies since it is a conservative, simple and quick procedure that may be performed in the dental office settings during initial consultation. [25]

The limitation of this technique is the possibility of recurrence and the need to perform complementary procedures to release the tongue satisfactorily. [28]. As age advances, frenulum grows in length and normal function is established. Frenulectomy is recommended, if it persists. [14]

Frenectomy corresponds to the complete excision of the frenulum. This procedure is more invasive and difficult to be performed in young children, although the results are more predictable, decreasing the recurrence rate. [29,21]. Each of these procedures (frenotomy or frenectomy) involves surgical incision, establishing hemostasis, and wound management. Dressing placement or the use of antibiotics is not necessary because infection is distinctly uncommon.

Nowadays, other techniques are used in the treatment of ankyloglossia. The use of electrosurgery or laser technology for frenectomies has demonstrated a shorter operative working time, a better ability to control bleeding, reduced intraand post-operative pain and discomfort, fewer postoperative complications. These procedures require special instruments, extensive training as well as skillful technique and patient management. [13]

The Myofunctional therapy is a program of specific exercises that strengthen the tongue. The myofunctional rehabilitation begins one week before the surgical intervention, and the patient is explained the lingual praxis that will be carried out in the following weeks. The objective of this protocol is that the patient learns the exercises without pain. [30]

Thus, Collaboration with the speech therapist is necessary to complete the therapeutic approach. [23]

\section{Conclusion}

Through this clinical case, we have shown the interest of a careful clinical examination in children to make early diagnosis of lingual dysfunction, and in order to choose the best therapeutic approach. If not well treated, in fact, it can create problems not only related to feeding and speech, but also involving growth and posture.

\section{Source of Support: Nil \\ Conflict of Interest: None \\ Permission of IRB: Yes}

\section{References}

1. Hall DM, Renfrew MJ. Tongue tie. Arch Dis Child. 2005 Dec;90(12):1211-5.

2. Dezio M , Piras A., Gallottini L, Denotti G. Tonguetie, from embriology to treatment: a literature review. Journal of Pediatric and Neonatal Individualized Medicine 2015;4(1):e040101 doi: 10.7363/040101.

3. Chaubal TV, Dixit MB. Ankyloglossia and its management. J Indian Soc Periodontol. 2011 Jul;15(3):270-2. doi: 10.4103/0972-124X.85673.

4. Messner AH, Lalakea ML. Ankyloglossia: controversies in management. Int $\mathrm{J}$ Pediatr Otorhinolaryngol. 2000 Aug 31;54(2-3):123-31.
5. Fleiss PM, Burger M, Ramkumar H, Carrington P. Ankyloglossia: a cause of breastfeeding problems? J Hum Lact. 1990 Sep;6(3):128-9.

6. Hogan M, Westcott C, Griffiths M. Randomized, controlled trial of division of tongue-tie in infants with feeding problems. J Paediatr Child Health. 2005 MayJun;41(5-6):246-50.

7. Jorgenson RJ, Shapiro SD, Salinas CF, Levin LS. Intraoral findings and anomalies in neonates. Pediatrics. 1982 May;69(5):577-82.

8. Marmet C, Shell E, Marmet R. Neonatal frenotomy may be necessary to correct breastfeeding problems. J Hum Lact. 1990 Sep;6(3):117-21.

9. Chu MW, Bloom DC.Posterior ankyloglossia: a case report.Int J PediatrOtorhinolaryngol. 2009;73(6):8813.doi: 10.1016/j.ijporl.2009.02.011. Epub 2009 Mar 20.

10. Harris EF, Friend GW, Tolley EA. Enhanced prevalence of ankyloglossia with maternal cocaine use. Cleft Palate Craniofac J. 1992 Jan;29(1):72-6.

11. Hong P, Lago D, Seargeant J, Pellman L, Magit AE, Pransky SM. Defining ankyloglossia: a case series of anterior and posterior tongue ties. Int $\mathrm{J}$ Pediatr 
Otorhinolaryngol. 2010 Sep;74(9):1003-6. doi: 10.1016/j.ijporl.2010.05.025. Epub 2010 Jun 16.

12. Segal LM, Stephenson R, Dawes M, Feldman P. Prevalence, diagnosis, and treatment of ankyloglossia: methodologic review. Can Fam Physician. 2007 Jun;53(6):1027-33.

13. Clinical Affairs Committee, American Academy of Pediatric Dentistry. Guideline on Management Considerations for Pediatric Oral Surgery and Oral Pathology. Pediatr Dent. 2015 Sep-Oct;37(5):8594.

14. Ankur AS., Pradeep B, Satyanarayana N , Ruchi K, Varun K, Neha K, Sunitha P, ReddyN. Ankyloglossia, Rare anomaly of tongue in adults: A case study. Journal of College of Medical Sciences-Nepal,2010,Vol-6, No3, 37-39

15. Kotlow LA.Ankyloglossia (tongue-tie): a diagnostic and treatment quandary, Quintessence Int. 1999;30 (4):259-62.

16. Hazelbaker AK. The Assessment Tool for Lingual Frenulum Function (ATLFF): Use in a lactation consultant's private practice.Pasadena: Pacific Oaks College, 1993.

17. Amir LH, James JP, Donath SM. Reliability of the hazelbaker assessment tool for lingual frenulum function. Int Breastfeed J. 2006 Mar 9;1(1):3.

18. Verdine V A and Khan R. Management of ankyloglossia- Case reports. IOSR Journal of Dental and Medical Sciences 2013; 6(4):31-33.

19. YaredK FG, ZenobioEG, Pacheco W. Aetiologiamultifatorial da recessão periodontal. R Dental Press OrtodonOrtop Facial. 2006 NovDec;11(6):45-51.

20. Geddes D, Langton D, Gollow I, Jacobs L, Hartmann P, Simmer K. Frenulotomy for breastfeeding infants with ankyloglossia: Effect on milk removal and sucking mechanism as imaged by ultrasound. Pediatrics 2008; 122(1):e188-e194.
21. Lalakea ML, Messner AH. Ankyloglossia: does it matter? Pediatr Clin North Am. 2003 Apr;50(2):381-97.

22. MeloNSFO, Lima AAS, Fernandes A, Silva RPGVC. Ankyloglossia: case report. RSBO. 2011 JanMar;8(1):93-8

23. Olivi G, Signore A, Olivi M, Genovese MD. Lingual frenectomy: functional evaluation and new therapeutical approach. Eur J Paediatr Dent. 2012 Jun;13(2):101-6.

24.Randon A. Glossoplastie et freinectomie du point de vue de l'orthophoniste Réeducation orthophonique 2006, vol. 44, no 226 (164 p.)

25. Lalakea L, Messner A. Frenotomy and frenuloplasty: if, when and how. Oper Tech Otolaryngol Head Neck Surg. 2002;13(1):93-97. Doi : 10.1053/otot.2002.32157.

26. Suter VG, Bornstein MM. Ankyloglossia: facts and myths in diagnosis and treatment. J Periodontol. 2009 Aug;80(8):1204-19. doi: 10.1902/jop.2009.090086.

27. Segal LM, Stephenson R, Dawes M, Feldman P. Prevalence, diagnosis, and treatment of ankyloglossia: methodologic review. Can Fam Physician. 2007 Jun;53(6):1027-33.

28. Junqueira MA, Cunha NN, Costa e Silva LL, Araújo LB, Moretti AB, Couto Filho CE, Sakai VT. Surgical techniques for the treatment of ankyloglossia in children: a case series. J Appl Oral Sci. 2014 Jun;22(3):241-8.

29. Manfro AR, Manfro R, Bortoluzzi MC. Surgical treatment of ankyloglossia in babies--case report. Int J Oral Maxillofac Surg. 2010 Nov;39(11):1130-2. doi: 10.1016/j.ijom.2010.06.007. Epub 2010 Jul 7.

30. Ferrés-Amat E, Pastor-Vera T, Ferrés-Amat E, Mareque-Bueno J, Prats-Armengol J, Ferrés-Padró E. Multidisciplinary management of ankyloglossia in child hood. Treatment of 101 cases. A protocol. Med Oral Patol Oral Cir Bucal. 2016 Jan 1;21(1):e39-47.

\section{How to cite this article?}

FZ. Benkarroum , Fawzi R, Management of tongue-tie in children: a case report: Int J Pediatr Res 2016;3(4):252259.doi:10.17511/ijpr.2016.i04.08. 